Derecho \& Realidad

Núm. 21 • I semestre de 2013

Facultad de Derecho y Ciencias Sociales, UPTC

ISSN: 1692-3936

\title{
La regresión inefectiva de los derechos en Colombia mediante las sentencias de constitucionalidad
}

¿Constituye el fenómeno de cosa juzgada un obstáculo en el desarrollo del principio de progresividad de los derechos? ¿En qué casos se ha constituido una regresión de los derechos inefectiva sujeta al fenómeno de cosa juzgada?

In effective regression of rights in Colombia by the constitutional sentences

Is the phenomenon of res judicata an obstacle for the development of the principle of escalation of rights? In which cases has been an ineffective regression of rights subject to the phenomenon of res judicata?

Semillero de Investigación de Derecho Procesal*

\section{Resumen}

El objetivo general de este trabajo es analizar el principio de progresividad de los derechos, a la luz de la jurisprudencia constitucional y de los principios propios del Estado social de derecho, y establecer en qué casos y bajo qué argumentos se ha constituido una regresión no justificada de los derechos, que no vuelve a revisarse por aplicación de la cosa juzgada, determinando como

\footnotetext{
* Semillero de Investigación de Derecho Procesal, de la Facultad de Derecho y Ciencias Sociales de la Universidad Pedagógica y Tecnológica de Colombia, coordinado por el docente Edison Porras.
} 
instrumento argumentativo que en esta ponencia se tendrá un desarrollo dialéctico.

De manera más específica se precisará, en primer lugar, el alcance del test de no regresividad de los derechos y su aplicación en las sentencias de constitucionalidad, y, de esta manera, se determinarán los argumentos de la Corte, para que sus sentencias permitan la regresión de los derechos, en ciertos casos en que pueda considerarse inefectiva. Como punto final se presentará una propuesta que proporcione una solución al problema jurídico eje de esta ponencia: ¿Qué alternativa puede sugerir el grupo investigador para estos casos de no efectividad en los fines estatales cuando ha existido regresión de derechos?

\section{Palabras clave}

principio de progresividad, derechos, jurisprudencia constitucional, cosa juzgada, regresividad.

\section{Abstract}

This work analyzes, as general objective, the principle of progressivity of rights, from the constitutional jurisprudence and the principles inherent to the social rule of law, and to establish in which cases and under what grounds has been anunjustified regression of rights, which is not reviewed because of application of res judicata, determining that this paper will have a dialectical development.

We will establish specifically, first, the scope of non regression test of rights and its application in the sentences of constitutionality, and thus to determine the arguments of the Constitutional Court and that its statements may prompt the regression of rights in certain cases that can be considered ineffective. As a final topic we will present aproposal to provide a solution to the legal problem of this paper: what alternative may suggest the research group for these cases of effectiveness of the state purposes when there has been regression of rights?

\section{Key words}

principle of progressivity, rights, constitutional jurisprudence, res judicata, regressivity. 


\section{Introducción}

El Estado social de derecho, una de las máximas conquistas de la humanidad, un espacio jurídico en el cual no sólo hay que observar las normas y el respeto por ellas, sino, ante todo, el valor kantiano que diferencia los objetos de los seres humanos: la dignidad.

Con el Estado social de derecho nace una nueva concepción del individuo, que de ser considerado medio en fines estatales, pasa a ser un fin en sí mismo, realizado por el Estado y respaldado por el derecho. Dentro de esas grandes conquistas hechas por la humanidad, se halla el principio de progresividad de los derechos ganados por una sociedad. Efectivamente, a la luz de nuestro modelo de Estado, existe una prohibición expresa de regresión de los derechos, tanto en materia legislativa como constitucional.

En Colombia, la labor de la Corte Constitucional en torno a la excelsa función de guarda y supremacía de la Constitución y del catálogo de derechos que en ella se contiene, ha sido loable. Nadie duda de los alcances que en términos, no sólo jurídicos sino sociales, han tenido las sentencias de este máximo tribunal constitucional. El esmero argumentativo-jurídico y la conciencia social de nuestros magistrados constitucionales desde el año de 1991, se ha visto reflejada en un sinnúmero de sentencias, que han dado soluciones reales no sólo a la situación de tutelar derechos cuando se revisan las decisiones de otros jueces, sino en materia de revisión y control de la constitucionalidad de la actividad legislativa, con beneficios aún más grandes, cuando del examen de normas generales se trata.

Ubicados en la calidad del examen de constitucionalidad que hasta el momento se le ha dado a la normatividad, surge en el grupo una inquietud. Al ser Colombia un país con una realidad social bastante compleja, ha sido necesario buscar equilibrios al reconocer o no determinados derechos. Debido a la cultura tercermundista que vivimos hoy en día, es necesario que algunos fines estatales se prioricen sobre la aplicación de ciertos derechos, debido a la complejidad de nuestra sociedad, donde a veces se pueden realizar algunas cosas y otras, no.

Regresión de los derechos, para los efectos de esta ponencia, es la situación que se presenta cuando por dar prioridad al cumplimiento de algún fin de interés general, se retrocede en el alcance que se le ha dado a ciertos derechos. En materia legislativa, esto es frecuente, sobre todo en sociedades del tercer mundo, como hemos expresado.

Sin embargo, cabría aquí preguntarnos si acaso este fenómeno de regresión ha permeado la jurisprudencia constitucional. La respuesta inmediata es afirmativa. La misma Corte Constitucional en su sentencias de control abstracto, reconoce que existe incluso un test de no regresividad, y ha justificado en muchas de sus sentencias 
que en pro de finalidades estatales, se retroceda, como ha quedado dicho, en los alcances de determinados derechos, aplicando o no el test respectivo. No es esa una novedad, ni tampoco un problema jurídico sin respuesta para el grupo, la pregunta que es problemática es un tanto más compleja.

¿Qué ocurre cuando al privilegiar unas situaciones, y, por lo tanto, retrocediendo el alcance de algunos derechos, mediante una sentencia de constitucionalidad no se obtienen los resultados esperados, verbi gracia, cuando se renuncia al alcance de un derecho para conseguir un fin estatal, pero tal fin no se consigue a lo largo del tiempo?

Muchos pensarían que la solución es simple, si una demanda de constitucionalidad adelantada ante la Corte, dio lugar a la regresión inefectiva, pues otra demanda tendría que dar lugar al restablecimiento de esos derechos que se hallaren retrocedidos; pero en la práctica eso no es tan cierto, sencillamente porque el fenómeno de la cosa juzgada, como garantía y fundamentodel debido proceso, es utilizado por la Corte para no hacer de nuevo un análisis de constitucionalidad, quedando así vigente una norma que, además de regresiva, es inefectiva. ¿Qué hacer ante esto, en las situaciones reales de nuestro país?

A fin de dar una contestación a este problema jurídico, desprendido directamente de las sentencias de Constitucionalidad de la Corte, se estructura la siguiente ficha argumentativa de la ponencia.

Este instrumento argumentativo consta de tres partes fundamentales: se desarrollará conforme a máximas de dialéctica para dar efectiva respuesta al problema jurídico objeto del título y objeto de la investigación: en primer lugar hay una tesis que muestra un genérico estado de la cuestión del test de no regresividad de los derechos, ajustado a las referencias que en diferentes sentencias de control abstracto ha hecho la Corte Constitucional. Mediante una antítesis, el grupo muestra dos eventos específicos en los cuales esta regresión de derechos ha sido inefectiva y argumenta en torno al fenómeno de la cosa juzgada, cómo esta puede ser tomada como un obstáculo cuando se intentan reivindicar aquellos derechos en que se ha retrocedido y cuyos fines privilegiados no se han cumplido. Por último, el grupo elabora una síntesis, que se ha denominado propuesta para solucionar el problema de investigación, y presenta una conclusión de carácter jurídico social.

La presente ponencia se estructura además por medio de subtítulos, toda vez que los temas por tratar son varios y jurídicamente relevantes en cuanto a sus implicaciones, y se apoya fundamentalmente en argumentos del grupo y en sentencias de constitucionalidad proferidos por la Corte, debido a la escasa doctrina que el grupo encontró en relación directa con el tema. 
Derecho y Realidad

\section{Tesis: la regresión de los derechos no es novedad en materia de control abstracto de constitucionalidad}

La Constitución Nacional recoge el principio de no regresividad como medio de protección de los derechos alcanzados en una sociedad. De manera genérica, podríamos hablar de la imposibilidad de retroceder en el reconocimiento de derechos que favorecen al asociado y de un amplio resguardo con sustento constitucional que lo impediría.

Así, siguiendo a la Corte Constitucional en una de sus sentencias(2011, C-228):

El principio de progresividad de los derechos implica que una vez alcanzado un determinado nivel de protección no se puede retroceder frente él, la amplia libertad de configuración del legislador se ve restringida, al menos en un aspecto: todo retroceso frente al nivel de protección alcanzado es constitucionalmente problemático puesto que precisamente contradice el mandato de progresividad.

Resulta demasiado idealista considerar que en un Estado social de derecho como el nuestro, moderno, de modelo principalmente neoliberal, y con las implicaciones que ello trae, una vez reconocidos los derechos, estos permanecerán estáticos. El constante movimiento de las instituciones económicas y sociales y el cambio de los tiempos hacen que se evidencien necesidades en las personas que discrepan de las ya reguladas $\mathrm{y}$, por tanto,en muchas ocasiones es primordial un cambio legislativo.

Por lo anterior es que se ha implementado en nuestra legislación la posibilidad de hacer regresión de los derechos con el único fin de favorecer las necesidades de carácter general. A este respecto, la honorable Corte Constitucional ((2011, C-228)ha sostenido que dicho "retroceso debe presumirse en principio inconstitucional, puede ser justificable, y por ello está sometido a un control judicial más severo. Para que pueda ser constitucional, las autoridades tienen que demostrar que existen imperiosas razones que hacen necesario ese paso regresivo en el desarrollo de un derecho social". Es en esa justificación donde debe hacerse evidente el deseo de satisfacer una necesidad que sobrepasa el plano de lo personal.

Cabe resaltar aquí que el derecho adquirido que pretende ser remplazado, en la mayoría de ocasiones es personal y que de alguna manera se sacrifica con el único fin de alcanzar objetivos favorables a la sociedad; esta es la razón substancial que justifica su desmedro.

Pero la decisión de menoscabo de los derechos adquiridos no se ha de tomar de una manera aislada y sin razonamiento o argumentación alguna, pues traería como consecuencia una incuestionable inseguridad jurídica por la vulneración al principio de legalidad. 
Es así como la Corte Constitucional ha implementado un test de regresividad tendiente a verificar la necesidad real de hacer regresión de unos derechos a favor de otros. Este test tiene como componentes los ya mencionados en la sentencia C-228-2011, que son:

Cuando se constata la regresividad de un derecho a través de una reforma, se debe estudiar (i) si con la reforma no se desconocieron derechos adquiridos; (ii) si se respetaron con la reforma los principios constitucionales y (iii) si las reformas se encuentran justificadas conforme al principio de proporcionalidad y razonabilidad.

El test de proporcionalidad en materia de regresividad de los derechos sociales ha utilizado los tres pasos que se plantean en el juicio de igualdad, es decir el principio de idoneidad que consiste en verificar si la medida regresiva tiene un fin constitucionalmente legítimo y un presupuesto constitucional que la justifique, en segundo lugar el presupuesto de la necesidad en donde se valora si de todas las medidas posibles, la que escogió el legislador es la menos regresiva, hasta llegar hasta al último paso del test de verificar la proporcionalidad en sentido estricto que consiste en confrontar el principio de no regresividad con otros principios constitucionales como la garantía de sostenibilidad del sistema o los principios de universalidad, solidaridad y eficiencia, para establecer si en el caso concreto se presenta un mayor menoscabo del principio de progresividad frente al principio constitucional que se enfrenta a éste.

No es fácil tomar esta clase de decisiones atendiendo a la relatividad de opiniones, pues una medida regresiva para un derecho individual debe tener plena incidencia en la seguridad y progreso de un derecho que favorezca a la sociedad en general y no solo convencer de ello a quienes toman la decisión sino que debe demostrar con resultados que la medida regresiva no lesionó un derecho sin beneficiar otro de mayor incidencia social.

Por ello, la Corte Constitucional (2004, C-038) no ha de quedarse únicamente con el estudio anterior sino que seguidamente debe constatar,

(i) que las medidas no fueron tomadas inopinadamente sino que se basaron en un estudio cuidadoso, (ii) que el Congreso analizó otras alternativas, pero consideró que no existían otras igualmente eficaces que fueran menos lesivas y (iii) finalmente debe el juez constitucional verificar que la medida no sea desproporcionada en estricto sentido, esto es, que el retroceso en la protección del derecho no aparezca excesivo frente a los logros.

El estudio y las conclusiones anteriores no serán suficientes para volver determinante una medida regresiva, no será tomado, una vez hecho, como la gran solución al 
problema social, sino que deberá arrojar unos resultados en un tiempo determinado que permitan comprobar si tal medida mejoró o no la calidad de vida de los asociados.

Así, el mero estudio será solo el inicio de una "teoría" que habrá de ser comprobada para que la regresión de los derechos continúe vigente; si los resultados arrojados no benefician, como en teoría se planteaba, la medida regresiva habrá de revocarse y volver a su estado anterior.

Por ello se ha establecido que, cuando una medida regresiva es sometida a juicio constitucional, corresponderá al Estado demostrar, con datos suficientes y pertinentes, (1) que la medida busca satisfacer una finalidad constitucional imperativa; (2) que, luego de una evaluación juiciosa, resulta demostrado que la medida es efectivamente conducente para lograr la finalidad perseguida; (3) que luego de un análisis de las distintas alternativas, la medida parece necesaria para alcanzar el fin propuesto; (4) que no afectan el contenido mínimo no disponible del derecho social comprometido; (5) que el beneficio que alcanza es claramente superior al costo que apareja. (Corte Constitucional, 2011, C- 228).

Tendrá entonces que hacerse una integración constitucional para determinar las necesidades imperativas, hecho que tiene su apología en el principio del bien común sobre el bien personal y el principio mismo del Estado social de derecho. Deberá tenerse en cuenta sobre qué comunidad recaerá principalmente el menoscabo, si vale la pena empeorar la situación de unos aduciendo que la medida los mejora, y si es la mejor forma de conseguir la "evolución" del estado.

Cuando los anteriores resultados no se ponen de presente, no tendrá sentido la adopción de medidas regresivas, se tendrá que revaluar su función y como consecuencia se habrá de asumir de nuevo el cambio legislativo que solucione la situación y vuelva a conceder los derechos adquiridos inicialmente y que fueron desconocidos por la implementación de la postura que en teoría fuera favorable a la sociedad.

En lo andado hasta acá, no ha habido mayor dificultad, es sencilla y legítima la presentación que mediante su jurisprudencia ha hecho la Corte Constitucional y queda expuesta entonces la relevancia del tema de regresión de derechos, para abrir las puertas ahora a los argumentos que el grupo expone como antítesis.

\section{Antítesis: de la regresión de los derechos laborales a la inefectividad en el aumento del empleo en Colombia, que es cosa juzgada}

En materia de regresión de derechos se refleja en un $90 \%$ los ejemplos, en aquellos de carácter social económico y cultural, si bien el control que ha hecho nuestra Corte 
Constitucional en aspectos que pueden llevar a un desconocimiento del principio de progresividad no responde más que al cumplimiento de los fines de nuestro Estado social de derecho y siempre confiados en el acatamiento de sistemas que como el Comité de Derechos Económicos, Sociales y Culturales de Naciones Unidas, intérprete autorizado del PIDESC, que para explicar en términos genéricos es el órgano de expertos independientes que supervisa la aplicación del Pacto Internacional de Derechos Económicos, Sociales y Culturales por sus Estados Partes ${ }^{1}$.

Todos los Estados Partes deben presentar al Comité informes periódicos sobre la manera en que se ejercitan esos derechos. Inicialmente, los Estados deben presentar informes a los dos años de la aceptación del Pacto y luego cada cinco años. El Comité examina cada informe y expresa sus preocupaciones y recomendaciones al Estado Parte en forma de "observaciones finales". Este organismo ha acogido la necesidad de reglamentar aquellas circunstancias en las que se hace realmente necesario volver a situaciones anteriores en las que no existían reconocimientos a determinados derechos; vale la pena cuestionarnos acerca de la efectividad de los mismos, ya que, aunque los objetivos por los que se puede llegar a un retroceso en materia de derechos se cumplen, la sociedad no está más que enfrentando una realidad en la que sacrificar sus derechos representa la ganancia de otros en pro del bienestar social.

El verdadero problema radica en el seguimiento y control que se hace a cada una de esas situaciones regresivas, pues aunque la decisión legislativa o la de control constitucional en abstracto, se tome con conciencia suficiente de la necesidad de privilegiar un interés general, en relación con el juicio de proporcionalidad hecho con anterioridad, expresa o tácitamente, ese mismo interés nos obliga a buscar la forma más efectiva y eficiente de verificación del cumplimento de esos objetivos por los que se ha considerado la aceptación del retroceso.

Para hacer un poco más clara nuestra visualización, tomaremos un ejemplo que puede ser visto a la fecha como el más debatido en materia laboral.

La expedición de la ley 789 de 2002 trajo consigo algunas modificaciones al Código Sustantivo del Trabajo, entre las más sobresalientes para este efecto, podemos considerar las contenidas en el capítulo VI, denominado Actualización de la relación laboral, artículos 25, 26, 28, así como el artículo 51. Todas ellas modificatorias de las garantías laborales que gobernaban la relación, es así como se cambia la consideración del horario de la jornada ordinaria diurna, pues esta ya no iría hasta las seis de la tarde sino hasta las diez de la noche, reduciendo el tiempo en que el

El Comité se estableció en virtud de la resolución 1985/17, de 28 de mayo de 1985, del Consejo Económico y Social de las Naciones Unidas (ECOSOC) para desempeñar las funciones de supervisión asignadas a este Consejo en la parte IV del Pacto (www.ohchr.org/spanish/bodies/ cescr/). 
trabajador podría obtener el respectivo recargo nocturno. En el recargo por trabajo dominical también se presenta modificación al ser reducido al $25 \%$. El articulo 28 reduce la indemnización por despido injusto y el articulo 51 introduce la posibilidad de flexibilización de la jornada laboral a partir del acuerdo entre trabajador y empleador (Corte Constitucional, 2004, C-038).

Todas estas modificaciones llevaron a diversos analistas a una conclusión general: el desmejoramiento de las condiciones laborales en nuestro país, sustentado en la búsqueda de formas de fomentar el empleo y ampliación de la economía nacional, denominada por el legislador "empleabilidad"; pero puede que este no sea nuestro punto controversial, pues el mismo legislador consciente del desmejoramiento de condiciones producido por esta circunstancia, propuso la creación de la Comisión de seguimiento y verificación de las políticas de generación de empleo, quienes después de dos años de vigencia de la ley, deberían presentar una completa evaluación de los resultados de la Ley 789 de 2002, facultando al Gobierno nacional, a partir de la rendición del informe, para presentar al Congreso un proyecto de ley que modificara o derogara las disposiciones que no hubieran logrado efectos prácticos para la generación de empleo. (Congreso de la República, 2011)

Esta es una medida de control y seguimiento que sin duda encaja en nuestro Estado, que lucha a diario contra la degradación de los derechos y el reconocimiento de condiciones dignas de vida, las cuales llevan implícitas condiciones dignas de trabajo. Pues bien, el tema que nos trae a esta discusión lo encontramos en la situación que puede verificarse con posterioridad, como era de esperarse, y ante la afectación que encontramos, las demandas por inconstitucionalidad del articulado de esta ley no dieron espera, y es así como en sentencia C-038 de 2004, la Corte Constitucional tuvo que pronunciarse sobre la constitucionalidad del mismo. En esta oportunidad la Corte realiza su estudio a partir del siguiente problema jurídico: ¿hasta qué punto es constitucionalmente legítimo reducir ciertas garantías de los trabajadores reconocidas por el ordenamiento con el fin de promover el empleo de quienes carecen de trabajo?

A partir de ello se propuso verificar si dicha disposición vulneraba derechos adquiridos y el principio de favorabilidad, concluyendo que la norma no modificaba situaciones consolidadas sino meras expectativas, por lo que no estábamos en presencia de derechos adquiridos, (aunque no por ello la medida se hizo menos regresiva) y por otra parte, que el principio de favorabilidad no impedía la modificación normativa al introducir situaciones menos benéficas al trabajador; sin embargo, la libertad que encuentra el legislador al introducir modificaciones en materia laboral que disminuyan las garantías de los trabajadores, NO es plena y debe atender a la verificación del cumplimiento de otras fundamentales como lo son el respeto por los principios constitucionales del trabajo y la justificación de las medidas conforme al principio de proporcionalidad, para obtener un propósito de relevancia constitucional. En torno a este principio, 
la Corte verificó el estudio y análisis previo así como la proporcionalidad de la medida, encontrándola ajustada al marco constitucional con un fin específico y totalmente legítimo, por lo cual se declaró su constitucionalidad. No obstante, en dicha sentencia se menciona la verificación del mencionado objetivo a partir de la Comisión que para tal fin dispuso el legislador, lo que hacía aún más evidente su constitucionalidad, aunque en concepto de muchos limitada a los resultados que se desprenderán del estudio de dicha comisión.

Aunque jurídicamente los "recargos" se toman como derechos inciertos y discutibles, cabría preguntarnos si socialmente es mera expectativa que aun cuando ya se ha puesto el sol, la jornada siga llamándose diurna, como si no se conociera que en nuestro país, las condiciones para trabajar, aún antes de las diez de la noche, son complejas, y deberían merecer un tratamiento diferente.

Recayendo en el tema expresado anteriormente, para el año 2006 la Comisión mencionada se disolvió, y en palabras del exprocurador general de la Nación, Edgardo Maya Villazón, la ley "no cumplió sus funciones de recuperar espacio para la generación de un empleo digno, aliviar la situación de los desempleados y permitir que accedieran a la seguridad social” (Congreso de la República, 2011).

Bastaría para nosotros, simples espectadores, fijarnos en las condiciones de desempleo que a diario se nos muestran en los medios de comunicación, para entender que en efecto le asiste la razón al funcionario exprocurador. La norma no pudo satisfacer sus finalidades, ya que pudo ser que el medio idóneo en la solución del desempleo no fuera una medida regresiva, pues hay condiciones económicas, sociales y políticas que influyen de manera directa e indirecta en la problemática generalizada del desempleo, que es aquello que, como se ha dicho, pretende la norma cuestionada, así que entonces se desprendería la necesidad de que al adoptar la medida regresiva un tinte de no idoneidad en la solución del problema, habría que revertirla y considerarla existencia de otros factores que deban ser solucionados en el interior del Estado y la sociedad.

En vista de estas circunstancias, el demandante inicial ante la Corte decide accionar de nuevo en busca del estudio de constitucionalidad, y en sentencia C-257 de 2008, se presenta a consideración de este máximo tribunal el estudio de constitucionalidad de dicha norma, en el que a pesar de las consideraciones del procurador del momento y la exposición del demandante, en la que se advertían nuevas circunstancias fácticas que hacían viable su estudio, la Corte encuentra que existe cosa juzgada constitucional y por tal razón se declara imposibilitada para fallar de fondo, ordenando estarse a lo resuelto en la sentencia C-038 de 2004.

Su decisión responde al análisis de las nuevas circunstancias fácticas presentadas por el actor, pues se encuentra que se fundamenta tan solo en un estudio de los muchos 
que se han realizado para verificar el cumplimiento de los objetivos, en tanto existen otros que, por el contrario, presentan resultados favorables y que invitan a la continuidad en el seguimiento y control, lo que impediría un fallo diferente pues los estudios no están unificados y tanta validez tendría que dársele a uno como a otro (Corte Constitucional, 2008, C-257).

Este ejemplo citado en nuestra antítesis se bifurca. En efecto, después de hecho el estudio por esta Comisión, la Corte se imposibilita ante la existencia de cosa juzgada y la única alternativa es la búsqueda de una nueva ley que derogue tácitamente la anterior, por lo que podemos identificar dos situaciones: la primera es la actitud del Gobierno para buscar una nueva reglamentación, y la segunda es la actitud de la Corte al considerar la existencia de cosa juzgada constitucional, siendo esta garantía del debido proceso, nuestro tema de estudio.

El análisis hecho de una ley que sometía su validez a la efectividad que la misma producía en aspectos económicos de la sociedad y más cuando de esta se desprende un retroceso del principio de progresividad, que sin los resultados esperados no encontraría fundamento alguno, que además de retroceso se convierte en violación al mismo principio y cuando los directamente afectados responden a un sector de la sociedad con tendencia de vulnerabilidad como lo son los trabajadores, a los que desde siempre se les ha considerado en un margen de desequilibrio frente a los empleadores, sin duda merecería unas consideraciones diferentes de las que se toman generalmente para hablar de de cosa Juzgada constitucional que no hace más que inocuos y desprotegidos los derechos de toda una sociedad.

No hace falta ir muy lejos para entender que han pasado ya casi seis años desde que la Comisión destinada para evaluar la eficacia de la ley, se disolvió, y que diversos estudios de la misma han considerado que ni siquiera había logrado llegar a la mitad de sus objetivos, que los empleos que durante esta época se habían logrado encontrar se dirigían más al resultado de la apertura económica (Congreso de la República, 2011) que a la ley implementada para tal fin. Seis años en los que a pesar de la evidente contradicción constitucional, esta normatividad aún sigue en nuestro ordenamiento contrariando el principio de progresividad que debe reinar en la protección de los derechos económicos sociales y culturales.

El DANE, por medio de informes oficiales (DANE, 2012), ha revelado que la tasa de desempleo en el mes de abril del presente año fue de $10.9 \%$, considerándose como una de las más altas de América Latina (Banco de la República, 2005); situación por demás preocupante, cuando a ello se suma que los problemas sociales que le son consecuencia siguen ante nuestros ojos en constante aumento.

Surgen interrogantes en torno a estos planteamientos: ¿Acaso no constituye una 
contradicción jurisprudencial el que primero exista un pronunciamiento limitado a la comprobación de efectividad de la ley, y que posteriormente cuando de forma expresa se determina la ineficacia de dicha ley, la Corte Constitucional haya evitado nuevamente un pronunciamiento ante la justificación de existencia de una cosa juzgada?

¿Cuál fue entonces el fundamento del primero y del segundo fallo?

¿Puede la Corte desconocer los principios y fundamentos de la cosa juzgada ante un evento como el que se trae a colación?

El primero de nuestro interrogante es el mismo que el honorable magistrado Jaime Araujo Rentería se plantea en el salvamente de voto de la sentencia C-257 de 2008. Hay que precisar que uno de los fundamentos claros para la declaratoria de exequibilidad de las normas demandadas responde a la existencia de un comité que verifica el cumplimiento de los objetivos que se sobreponían al retroceso en las garantías laborales, lo que en principio permitiría que si dichos objetivos no fuesen logrados, nos encontraríamos en presencia de un nuevo marco fáctico que posibilitaría un nuevo estudio de constitucionalidad de las normas, no obstante no estar expresamente señalado así en la sentencia inicial, si se desprende que el que se tomara como consideración la existencia del comité permite concluir su condicionamiento de eficaz, pues si fuese de otra forma de nada serviría el que la Corte hubiera verificado el control de medio más efectivo y de existencia de un fin legítimo sin la verificación de si este se cumplió o no.

Por ello, nuestra primera conclusión tiende al condicionamiento que se presenta en la sentencia C-038 de 2004 de la exequibilidad de las normas conforme al cumplimiento de los objetivos planteados.

Ahora bien, si en primera instancia la Corte realiza un condicionamiento de efectividad normativa, sería pues lógico que en un segundo momento se pudiese dar el análisis de fondo ante los diversos estudios que demuestran la efectividad o no de la norma, para concluir en última instancia si esta estaba acorde o no al ordenamiento constitucional (verificación de su finalidad), y no entregar un fallo que se remite a lo pronunciado en la misma sentencia en la que se condicionó, impidiendo su pronunciamiento por la existencia de cosa juzgada. Lo cual significa entonces que nos encontramos frente a una contradicción jurisprudencial, ya que independientemente del resultado del análisis,debió la Corte haber hecho un control de la exequibilidad del pronunciamiento inicial dejando clara su posición sin dar paso a discusiones en torno a la cosa juzgada y los efectos que socialmente sigue implicando la declaratoria de cosa juzgada, que en palabras de Couture,es la "autoridad y eficacia de una sentencia judicial cuando no existen contra ellas medios de impugnación que permiten modificarla". Lo que implica, como se ha expresado, que se sacrificaron algunos 
derechos, se regresaron, pero la realidad social no obtuvo la finalidad que se perseguía y ni hay reconocimiento a los derechos, ni cambian las condiciones sociales con la regresión, presentándose así un doble perjuicio para quienes deben ejercer su derecho, para el caso en mención, los trabajadores.

Así podemos encontrar:

En este caso en particular, es de observar que en la sentencia C-038/04 se aceptó la regresividad en los derechos constitucionales para darle el beneficio a ley de que funcionara, y hoy con la nueva demanda se trataba de cotejar la teoría con la realidad. Ahora esta Corte propone que nunca se puede volver a estudiar este asunto, lo cual contradice claramente la jurisprudencia reiterada de la Corte, como quedó expuesto.

Lo anterior resulta entonces pertinente para establecer los fundamentos de las sentencias que llevaron al problema jurídico que hoy nos planteamos. La primera de ellas, la sentencia C- 038 de 2004 presenta en su parte considerativa:

1. La inexistencia de derechos adquiridos pues estamos en presencia de situaciones No consolidadas sino de meras expectativas a adquirir.

2. Sin embargo la limitación de afectación va mas allá de los derechos adquiridos pues aunque estos no se han consolidado los principios constitucionales en materia laboral impiden la disminución de las garantías que ya se han reconocido en normatividades anteriores.

3. Tenemos entonces que la normatividad en estudio resulta contraria al principio de progresividad de los derechos configurándose un retroceso en las garantías.

4. Cuando nos encontramos en presencia de circunstancias que disminuyen las garantías obtenidas debe verificarse que estas después de un estudio realizado sean considerados como la que menos afectación produce y que la misma cumpla un fin legítimo.

5. La Corte encuentra que la generación de empleo es un fin legítimo y que el legislador realizó un estudio minucioso de las diversas posibilidades con que se contaban para el mismo fin siendo esta la que menos impacto causaba; que para la verificación de cumplimiento del fin se creó un comité citado con anterioridad de verificación el cual estudiaría a largo plazo la efectividad o no de la modificación.

6. Que a partir de lo anterior la Corte encuentra como acorde a la Constitución las medidas presentadas y procede a declarar su exequibilidad.

Respecto de la sentencia C- 257/ 2008:

1. La Corte encuentra improcedente la demanda en virtud de la existencia de cosa Juzgada formal relativa al interponer la demanda bajo las mismas normas y los 
mismos cargos de la demanda inicial.

2. Para La Corte no se demostró la existencia de un nuevo contexto normativo y fáctico para un nuevo análisis.

3. La verificación se otorgó por la ley, en cabeza del legislador a través de la comisión de seguimiento y control de las políticas de generación de empleo.

4. Según la Corte el informe que sustenta la demanda del accionante se contrapone al resultado de diversos informes expedidos en virtud del resultado de la reforma laboral

En virtud de lo anterior, la Corte determina que en el caso bajo análisis existe cosa juzgada formal relativa, en tanto los cargos analizados son los mismos de la demanda inicial.

Partiendo de los argumentos presentados por este alto tribunal, nos permitimos diferir de su pronunciamiento por dos razones: la primera de ellas, ya mencionada, es aquella en la que admitiendo la constitucionalidad inicial de la norma demandada, entre otros asuntos, debido a la existencia de un comité encargado de la verificación del cumplimiento o no de los fines previstos como sustento de la regresión, podríamos estar en presencia de un condicionamiento de efectividad. Si ello no fuere así, el argumento inicial no podría tener valor, y si dicho argumento no es verificado, como debió haber sucedido en virtud de la demanda, no estaría la Corte realizando un control que generara garantías para el cumplimiento constitucional. Era este entonces el evento perfecto para verificar la adecuación de la declaratoria de exequibilidad con la realidad, pues la teoría y los medios no son fundamento de adecuación constitucional sin un fin comprobado.

Lo anterior, más que demostrar un nuevo marco fáctico sería la comprobación del mismo sobre el que se dio la constitucionalidad, el cual no existía en dicho pronunciamiento pero si cumplía con un objetivo constitucional.

Como segundo evento, a título grupal se considera que la Corte no puede hacer mención a diversos informes sin estudiar de fondo la cuestión, pues es el informe el resultado del objetivo inicial planteado, independientemente de que este se hubiese cumplido o no, o cuál de ellos merecía mayor credibilidad; su fundamento debe remitirse a la existencia de los mismos y la valoración de los resultados obtenidos por una ley que si bien en principio fue constitucional, se encontraba limitada a su finalidad.

Se continúa entonces para absolver el último interrogante, que se genera partiendo de la ya mencionada posición en la que la Corte no debió haber declarado la existencia de cosa juzgada sino haber realizado un pronunciamiento que dejara sentada y verificada su posición de constitucionalidad.

Es claro que aunque el estudio de la última sentencia no se hizo a fondo, sí se dejaron 
expresados cuáles hubiesen sido los argumentos que en últimas habrían considerado como constitucionales las normas, pues los estudios que concluían su eficacia no eran uniformes y se tenían otros que contrariaban los presentados por el actor. Ante esta circunstancia, la duda hubiese sido resuelta a favor de la exequibilidad, tal como lo manifiesta el H.M. Humberto Sierra Porto en su salvamento de voto, pero cabe entonces preguntarnos ¿qué tanta intervención debió haber realizado la Corte, si los derechos en juego significan un retroceso de las garantías laborales? Si estábamos ante dos años de desconocimiento y al fin de cuentas sin resultado alguno, pues acudiendo a la lógica matemática estos se eliminarían y nos encontraríamos igual que al comienzo sin un estudio, sin un resultado, pero ante el retroceso de los derechos, no sería este entonces otro argumento para decir:

1. La Corte debió haberse pronunciado de fondo y no declarar cosa juzgada.

2. Su estudio, de haberse hecho con los argumentos someramente señalados, debió haberse dirigido a la protección de los derechos de los trabajadores, en cuanto a su progresividad se refiere, dando como resultado una posición de no cumplimiento de las finalidades previstas, pues al fin y al cabo no tenemos resultado aún, lo que resulta inconstitucional ya que nadie podría pretender que duremos dos años intentando aplicar una norma regresiva sin cumplimiento de los fines previstos, en palabras kelsenianas, lo que la hace ineficaz y sin posibilidad de ser aplicada (Kelsen, 1960). El mismo Dr. Sierra Porto manifiesta:

en este caso concreto debido a que se examinan medidas regresivas en materia de derechos económicos sociales y culturales, las cuales suponen un desconocimiento de la obligación de no retroceso que se desprende de claros mandatos constitucionales y de tratados internacionales de derechos humanos, las dudas acerca de las cuestiones empíricas relevantes, esto es, sobre los efectos de la reforma laboral en la generación de empleo deben resolverse en contra de la constitucionalidad de la las disposiciones acusadas.

Lo anterior nos conduce a la siguiente conclusión: son los derechos económicos sociales y culturales el resultado de las luchas en pro de dignificar al hombre y que por ende merecen un tratamiento especial a la luz de los principios constitucionales, son los que le corresponden a las personas por su rol en un determinado contexto social, por hallarse desprotegidos frente a una situación desigual con respecto a otros que podrían abusar de tal circunstancia. Así son derechos sociales en términos de la teoría de los derechos aquellos que:

fundamentalmente son referidos al trabajo, ya que la situación de necesidad en que se halla el trabajador, lo coloca en una posición susceptible de ser objeto de abusos, tal como había sucedido durante la revolución industrial, que fue una muestra más que elocuente de lo que pueden hacer los empleadores con sus 
empleados si no existen leyes que limiten su accionar. Es por ello que la ley toma posición para lograr equidad, estableciendo por ejemplo que las condiciones de trabajo deben ser dignas, que deben respetarse horarios de trabajo, impide o regula el trabajo de menores, concede vacaciones pagas, un salario mínimo vital, el derecho de agremiarse, el derecho de los gremios a la huelga, a concertar convenios colectivos de trabajo, a recurrir a la conciliación y al arbitraje, etcétera. En otros casos el estado interviene para proteger a aquellos miembros del cuerpo social que se hallan en situación de inferioridad y necesitan mayor atención por su estado de salud o por su edad avanzada, concediéndoles seguro social, pensiones y jubilaciones. (La Guía, 2000)

No resulta coherente que después de ocho años sin un resultado evidenciado de la efectividad de la norma, sigamos dependiendo del legislador para un cambio normativo acorde a las garantías constitucionales, cuando poseemos un guardián de la Constitución, como se referirá más adelante.

Ahora bien, por último podríamos pensar si en pro de esa protección debería la Corte encontrar otros medios más expeditos para la verificación del cumplimiento de los objetivos que le permiten en principio declarar la constitucionalidad de las normas en estudio, debió entonces la corte detenerse y limitar su pronunciamiento de forma clara, específica y con un límite de tiempo, hasta tanto no se verificara el cumplimiento de todos los objetivos planteados, evitando más de seis años de regresión en los derechos económicos y sociales y por ende desprotección de los trabajadores, o debió ella haber comisionado a un ente que después de un tiempo diera verdadero conocimiento del cumplimiento o no de la finalidad. Esta inquietud se abordará de nuevo en la propuesta.

\section{¿Por qué acudir a la Corte Constitucional y sus sentencias en control abstracto cuando el legislador podría proponer alternativas que resolvieran de fondo la regresión?}

En sí la regresión de derechos, considera el grupo, no es una situación que pueda resolverse con una normativa, sea de carácter legislativo o constitucional, puesto que las circunstancias que la justifican son problemas del Estado mismo, que tendría que hacer cambios desde la mentalidad de las personas, pasando por la cultura y terminando en las normativas y los recursos para cumplirlas.

Dicho esto, tenemos que si bien es cierto, la labor legislativa como función del Estado es fundamental, en nuestro país, para nadie es un secreto cuántos problemas han surgido cuando se trata de legislar. Se sabe que muchos de nuestros legisladores operan a veces movidos por intereses diferentes a los buscados en las normas, por dádivas o favores prometidos, por trámites puramente políticos o demagógicos, sus 
funciones no han sido cumplidas con el ahínco que precisa legislar, tomando en cuenta que es Colombia una "República unitaria centralizada políticamente"2, de donde se desprende que sólo el Congreso de la República está apto para legislar, el compromiso es fuerte y, como se ha reiterado, sin ánimo de cuestionar toda una labor legislativa, sí se sabe que muchas de las leyes que son promulgadas, no han obedecido al desarrollo de un estudio juicioso y que luego han recibido serias críticas como le ha ocurrido a la política criminal, por sólo citar un caso. Colocados en este contexto es que la Corte Constitucional, se "constituye", valga la redundancia, en un garante de aquellos derechos que puedan verse transgredidos, pues el control constitucional es ante todo una esperanza de restauración de los ideales del Estado social de derecho y de la optimización de las máximas que le dan lugar. De allí se desprende la importancia del control abstracto que realiza esta corporación y la necesidad de que cada vez sea más exigente.

\section{Posible regresión inefectiva en materia del derecho de acceso a la justica con la conciliación prejudicial como requisito de procedibilidad a través del fenómeno de cosa juzgada}

En este, el segundo ejemplo de la antítesis construida por el grupo, no ha existido un fenómeno de cosa juzgada materializado en una sentencia de constitucionalidad. El ejemplo de la conciliación prejudicial como requisito de procedibilidad es traído a colación por el grupo bajo un nuevo argumento de la antítesis: la existencia de una regresión de derechos en la sentencia, aun cuando la Corte no haya aplicado el test, (esto será un apoyo en la propuesta), pero que cumple los requisitos para que la medida declarada exequible haya sido regresiva, puesto que implica poner ciertos intereses generales por encima de unos derechos, que en este segundo ejemplo, radicalmente distinto, ya que no se trata de derechos sociales, sino de derechos procesales.

El problema jurídico planteado en este segundo ejemplo, es si existe o no una medida regresiva cuando con el fin de realizar la tan anhelada descongestión de los despachos judiciales, se está restringiendo el acceso a la administración de justicia y el derecho de acción condicionándola a un requisito de procedibilidad: la conciliación, y, en segundo lugar, si de existir aquella medida regresiva, podría luego demandarse ante la Corte Constitucional, ya que los despachos judiciales en la realidad social, adolecen de la misma congestión y dilación injustificada en la administración de justicia. En ese orden, pasa el grupo a exponer los siguientes argumentos.

\footnotetext{
Constitución Política de Colombia. Título I: De los principios fundamentales. Artículo 1. Colombia es un Estado social de derecho, organizado en forma de República unitaria, descentralizada, con autonomía de sus entidades territoriales, democrática, participativa y pluralista, fundada en el respeto de la dignidad humana, en el trabajo y la solidaridad de las personas que la integran y en la prevalencia del interés general.
} 
Seguramente nadie duda de lo amigable que resulta hablar de conciliación en el momento de administrar justicia, cuando las partes llegan a un acuerdo por su propia cuenta, sólo con la orientación de un conciliador y mejor aún, cuando pacíficamente dan soluciones a esos conflictos que dificultan sus relaciones personales y jurídicas cumpliendo tales acuerdos, se habla entonces, en estricto sentido de una reconstrucción del tejido social, de una creación de cultura de armonía. Sin embargo, no todo es pacífico, cuando se dice que tal conciliación debe ser obligatoria y se considera como un presupuesto procesal.

Es en este punto, donde el término conciliación empieza a generar argumentos "no conciliables", al ser un requisito de procedibilidad para poder ejercer los derechos de acción y acceso a la justicia, y es aquí donde surge de nuevo el interrogante ¿es la conciliación como requisito de procedibilidad, limitación del derecho constitucional del acceso a la justicia o una alternativa para evitar el desgaste judicial?

Jurídicamente, tomar la conciliación extrajudicial como "requisito de procedibilidad", según la doctrina de la Corte Suprema de Justicia, es "hablar de requisitos que inexcusablemente han de concurrir en todo proceso para la constitución válida de la relación jurídica-procesal". Eso, en términos reales, no es otra cosa que la obligatoriedad de acudir a la conciliación en ciertas materias que han sido ya legalmente establecidas, antes de ir a la jurisdicción para el reclamo de los derechos, so pena de generar nulidades procesales. La conciliación como requisito de procedibilidad es, entonces, un presupuesto del proceso.

Es sabido que la intención manifiesta del legislador al registrar la conciliación como un requisito de procedibilidad, no es otra que la de incorporar mecanismos que permitan atacar la congestión judicial que atormenta a un país como el nuestro, una justicia que avanza con bastante lentitud. El legislador considera entonces que es necesario que la conciliación sea uno de esos mecanismos y que se haga nula toda acción que la desconozca.

Mediante sentencia C- 598 del 2011, la Corte constitucional ha considerado exequible la conciliación como requisito de procedibilidad, bajo los preceptos de la necesidad de descongestión de despachos judiciales, ¿pero qué ocurre cuando aún hoy se hace notorio que la descongestión de los despachos y la efectiva administración de justicia, han seguido el mismo camino de lentitud que la ha caracterizado? ¿Será que al demandar de nuevo la norma por inefectiva, la Corte diría válidamente "cosa juzgada" y tendríamos que esperar a que ese análisis en algún momento lo haga el legislativo? 
La discusión legislativa sobre la conciliación como requisito de procedibilidad no se ha agotado allí, la óptica del nuevo proyecto de Código General del Proceso, es tangencialmente diferente a ese amplio marco normativo del derecho procesal en Colombia. La exposición de motivos, presentada por el Instituto Colombiano de Derecho Procesal (2012), muestra que el eje de un nuevo Código que reúna los presupuestos básicos de todo proceso, es el derecho constitucional de la administración de justicia, por encima de toda formalidad o dilación injustificada, no se preocupa sólo de la descongestión de los despachos judiciales, sino del objetivo de un acceso a la justicia eficaz y oportuno, a este propósito refiere:

El Proyecto de Código General del Proceso fue elaborado, buscando que los procesos tengan una duración razonable, sin detrimento de las garantías de quienes acuden a la justicia como un medio de protección de sus derechos. Pero no se trata de acelerar por la rapidez en sí misma, sino de lograr una proximidad real entre la presentación de la demanda y la sentencia que salve al órgano judicial de la pérdida de confianza en él, por parte de la ciudadanía, lo cual conlleva a un deterioro de la democracia. El acceso a la justicia debe ser considerado como la acción de llegar a gozar de una justicia que tenga calidad y se concrete en una sentencia justa y pronta. Justa, cuando se le da la razón a quien la tiene desde el punto de vista del derecho.

Tenemos entonces que de acuerdo con el Proyecto de Código General del Proceso, estamos dejando de lado la conciliación como requisito de procedibilidad, ya que el proyecto presentado, pretende mencionarla sólo como un mecanismo alternativo de solución de conflictos, lo trata incluso como una etapa en el desarrollo dela audiencia, ya que dice:"Conciliación. Desde el inicio de la audiencia y en cualquier etapa de ella el juez exhortará diligentemente a las partes a conciliar sus diferencias, para lo cual deberá proponer fórmulas de arreglo, sin que ello signifique prejuzgamiento" (Instituto Colombiano de Derecho Procesal, 2012).

El proyecto insiste en el deber inicial del juez de intentar la conciliación dentro de la audiencia, pero en ninguna parte pretende figurar como un requisito de la demanda ni mucho menos como un presupuesto del proceso, todo esto con las implicaciones jurídicas que trae el que sea sólo un mecanismo para resolver pacíficamente un conflicto y dándole sentida prioridad al acceso a la justicia, retirando la conciliación como una obligación en el sendero del derecho de acción.

¿Las razones?, pueden ser varias, aunque ni la exposición de motivos ni el proyecto de Código las expresen, es claro que la discusión que en el mundo del derecho ha generado la obligatoriedad de la conciliación, habrá servido de apoyo a esta decisión de los miembros del Instituto para no presentar la conciliación prejudicial como obligatoria. 
Estudiemos entonces, uno a uno, los argumentos que en principio pudo tener el legislador para consagrar la obligatoriedad de la conciliación y veamos hasta qué punto en ellos aún sigue viva esa discusión y cómo a partir de esos, podemos inferir que ha existido una medida que además de regresiva es inefectiva.

Tenemos ciertamente la necesidad imperiosa de descongestión judicial. La conciliación prejudicial obligatoria podría ser una vía, pero ofrece algunos problemas cuando de hablar de "conciliación obligatoria" se trata. En primer lugar, resulta una contradicción ontológica hablar de conciliación obligatoria, puesto que la conciliación desde una definición contextual es un acto de libertad en el que dos partes se ponen de acuerdo para resolver sus diferencias. Si las partes implicadas en un proceso, son obligadas a conciliar, esa noción de libertad va opacándose, ya que de todas maneras, tengamos o no, el ánimo conciliatorio, tenemos que ir a cumplir con el trámite, como obligación que es.

Quienes llegan a una audiencia de conciliación lo hacen con total autonomía y voluntad de encontrar un medio diferente a la justicia ordinaria para alcanzar la solución de su conflicto, creando conciencia en quienes acuden del haber sido jueces de su propia causa. De tal forma que si las partes dentro de una conciliación han sido obligadas a asistir a la audiencia so pena de ser rechazada la demanda, se prescinde de la esencia de la autonomía de las partes para acudir a la conciliación, el obligarlos a asistir significa dirigirles su voluntad y un desconocimiento de la voluntad de aquellos que creen que su conflicto no es conciliable. Esto nos lleva a referir otros problemas acerca de obligar a conciliar, que es algo así como obligarnos a la paz, forzar la paz, en vez de construirla.Restándole a lo anterior la seguridad que para muchos representaba hasta el momento la conciliación, dándole un rango de exigencia, el presentarse a ella se convierte tan solo en el cumplimiento de un requisito sin ninguna profundización filosófica, olvidando que lo que se quiere es el reinado de la voluntad privada sin ninguna intervención de carácter estatal

En este sentido referimos aquí algunos juicios de Anita Giacometto(2007) en su texto Jurisprudencia constitucional en materia de conciliación prejudicial obligatoria, así:

En primer lugar, la celebración de la conciliación prejudicial obligatoria no proviene de la mera autonomía de la voluntad de las partes; dicha audiencia se celebra no porque las partes lo quieran o porque surgió de la iniciativa de quienes conforman el conflicto, sino porque la ley se los impone. En segundo lugar, si bien es cierto la implementación obligatoria de la conciliación prejudicial no contraría la Constitución, a mi juicio sí restringe el principio natural de la autonomía privada de la voluntad" (al cual ya hicimos referencia) por lo menos en el acceso a este medio alternativo de solución de conflictos, lo cual ocasiona que en muchos casos, las partes concurran a la audiencia de conciliación por 
miedo a la sanción, y no lleguen a ningún acuerdo. En último lugar, y no por ello menos importante, en consecuencia, se minimiza una de las finalidades perseguida con esta figura, cual es la de descongestionar la administración de justicia. Además, resulta de todo esto, que el hecho de hacer que la conciliación sea requisito de procedibilidad, la reduce a un mero trámite, ya que si en la conciliación no llegamos a un acuerdo, o tal acuerdo no se ha cumplido y acudimos finalmente a la jurisdicción, el primer paso que ha de seguir el juez en el desarrollo de la audiencia es "intentar la conciliación entre las partes", aquí podríamos preguntarnos si acaso la conciliación obligatoria no queda reducida a ser un requisito a agotar cuando el juez de todos modos, la intentará en todos los procesos.

Al ser reducida a un mero trámite, la conciliación pierde su naturaleza de mecanismo de solución de conflictos y se convierte de algún modo en un obstáculo para acceder a la justicia, en una dilación de aquello que finalmente va a pasar entre dos partes que están siendo forzadas por el imperio de la ley a conciliar, cuando no deseaban hacerlo y cuando finalmente querían que fuese un tercero quien pusiera orden en sus problemas.

En términos generales, el requisito de procedibilidad ha sido considerado por el Consejo de Estado (2006) como "limitaciones que, obedeciendo a determinadas finalidades superiores, la ley impone para el ejercicio de las acciones judiciales, de suerte que solamente en cuanto se acrediten los respectivos supuestos será jurídicamente viable acceder a la Administración de Justicia”. Nótese entonces que esta misma corporación alude al requisito de procedibilidad como una limitación al acceso a la justicia, situación que aunque la misma providencia no exprese, sí insinúa como limitación que es, puede convertirse en una dilación injustificada para el proceso.

Aquí podremos preguntarnos también si el hecho de que la conciliación como requisito de procedibilidad, dilate el acceso a la justicia, no termina haciendo que se sobrecarguen los ánimos en las partes forzadas a conciliar. En ese orden de ideas, se nos permitiría dudar sobre qué tanto descongestiona los despachos judiciales una conciliación obligatoria, cuando si no había un ánimo conciliatorio en ningún momento, vamos a terminar llevando nuestro proceso a los despachos, o si no, tendría que comprobarse la absoluta efectividad de los acuerdos firmados en una audiencia de conciliación, imaginémonos que si no son efectivas todas las actas de acuerdo cuando las partes hayan deseado la conciliación, con mayor razón dudaríamos de la efectividad de un acuerdo forzado, sólo por cumplir el trámite.

Insistimos que estos argumentos sólo pueden aplicarse a los casos en que "tocó conciliar", por obvias razones no aplican para aquellos casos en que las partes han deseado conciliar. 
Esto, para seguir sustentando que la conciliación prejudicial con el carácter obligatorio que le ha impreso el legislador, constituye una limitación al derecho constitucional de acceso a la justicia ya que tal proceso lo niega, obstaculiza y difiere; el que se le obligue al ciudadano común a agotar un requisito antes de acudir a la justicia ordinaria, limitando a los ciudadanos la posibilidad de acudir a la justicia formal por medio de un sistema que requiere expensas económicas y trámites tediosos que concluyen con la negación de la gratuidad de la justicia.

Podemos preguntarnos por ejemplo, qué pasa cuando una persona interesada en interponer una demanda no tiene dinero para conciliar en un proceso de mayor cuantía, porque como es sabido también, la conciliación prejudicial que se adelanta en centros de conciliación de consultorios jurídicos no puede exceder de la mínima cuantía Esto es muy común en materia de responsabilidad civil extracontractual, donde una persona de escasos recursos puede sufrir un daño de otra persona que amerite el reclamo de una gran suma de dinero por conceptos de daño emergente, lucro cesante, daño moral y daño a la vida en relación. De modo que esa persona al momento de querer agotar la conciliación extrajudicial, se encontrará con cualquiera de estas situaciones:

La conciliación no puede tramitarse de forma gratuita en un centro de conciliación de algún consultorio jurídico, o de una entidad pública, porque en dichos sitios existen topes que impiden realizar conciliaciones por cuantías determinadas. La conciliación no podrá tramitarse en un centro de conciliación particular, porque el interesado no puede pagar dicho trámite (si se quiere conciliar un asunto de más de 90 salarios mínimos, el valor de la conciliación puede llegar hasta el millón de pesos).

Entonces, qué hacer en estos casos, en los cuales el valor de la conciliación extrajudicial impide demandar en materia civil. Una persona en esta situación puede optar por las siguientes alternativas:

Bajar el monto de sus pretensiones y adecuar la cuantía a un valor que le permita acceder a una conciliación más económica. Pero una vez en la audiencia, no conciliar o intentar conciliación parcial. Si el asunto también debe conocerse por la jurisdicción penal, interponer la denuncia respectiva antes de la demanda civil. Si se trata de un delito querellable, el fiscal está en la obligación de agotar la conciliación antes de llevar el caso ante el juez. Se evidencia aquí que la gratuidad de la justicia sigue cuestionándose cuando estoy en la obligación de conciliar y esa conciliación puede salir más costosa que un proceso en la justicia ordinaria.

Recaemos ahora en el argumento del legislador, es decir, el de la descongestión de los despachos judiciales, pues por lo expuesto, la conciliación como requisito de procedibilidad no es el medio idóneo y por no serlo, no lleva al resultado esperado. 
Al fin y al cabo, como hemos dicho, las conciliaciones forzadas terminarían sin ninguna dificultad en los estrados judiciales, sólo retrasando la llegada de los procesos que congestionan y dilatando el acceso a la justicia de las partes en conflicto.

Lo mismo sucede en el caso de la conciliación en materia contencioso administrativa, pues es requisito de procedibilidad para poder accionar en determinadas materias, que los hoy denominados controles de nulidad y restablecimiento del derecho y las acciones de grupo, por ejemplo, sólo pueden hacerse efectivos ante la jurisdicción agotando el previo requisito de conciliar en la Procuraduría.

El trámite conciliatorio, que implica que en la solicitud de conciliación se eleven las pretensiones que pretenden hacerse valer en la justicia contenciosa, significa además una nueva situación que obliga a preguntarse si acaso este requisito no termina dilatando la justicia y por supuesto, obstruyendo el derecho de acción.

La conciliación en la materia reseñada, requiere autorización judicial para poder hacerse efectiva, en el evento de haberse celebrado un acuerdo entre la administración y la persona implicada. La aprobación respectiva hace tránsito a cosa juzgada, pero en términos reales entra a la jurisdicción como lo haría otro proceso. Esto referenciado también en el hecho de que exista un acuerdo parcial, donde lo acordado requiere una aprobación judicial, en el entendido que ya se ha expresado, y lo no acordado se irá igualmente a la jurisdicción contenciosa, efectuándose también en esta materia una clara regresión de los derechos, más aún cuando la justicia administrativa es, de por sí, en materia litigiosa un poco más demorada que otras.

Concluyendo, podemos referirnos también al objetivo conciliador que ha sido expuesto desde el principio de este texto: la conciliación pretende lograr un cambio cultural, cambio que de hecho no puede lograrse mientras se acuda a su obligatoriedad. Baste entonces decir que aun celebrado un acuerdo conciliatorio, precisamente por la cultura que reina en nuestro país, si este no se cumple, tenemos la vía del proceso ejecutivo, que sin ser secreto para nadie, se convierte en lo más frecuente, donde el acta de conciliación, se reduce a una parte del contenido de una nueva demanda: el título ejecutivo que le da lugar. Es decir, la conciliación así tomada, no es ya sólo un trámite sino un título, que, obviamente, se convierte en un nuevo proceso, que entra a la jurisdicción como los demás y que igualmente sólo consiguió retrasar la efectividad en la exigencia de unos derechos, en fin, regresarlos.

Por todo ello, si la conciliación se ha propuesto convertirse en una nueva cultura, que termine forjando la paz y reconstruyendo el tejido social averiado por los conflictos y la llamada justicia por la propia mano, debe ser entonces una cultura que se construya, que se necesite, que se persiga, pero jamás que se imponga. 
Los seres humanos siempre tenemos conflictos, la misma condición de humanidad nos garantiza que los conflictos siempre existirán y que no podemos forzarnos a solucionarlos, porque terminaremos alejándonos cada vez más del objetivo real, que es abordar y solucionar el conflicto. La construcción de una cultura de armonía es loable, y lograrla a través de la conciliación, sin duda es posible, pero nada nos alejaría más de construir esa cultura que el hecho de imponerla a las personas.

Es desde esa óptica que podría ser analizada como regresiva esta medida, y su análisis para haberla considerado exequible tendría que ser revisado de nuevo, eso sí, recayendo en la premisa de que el marco fáctico por analizar es nuevo, esto es, que no se haya dado un efectiva descongestión de los despachos judiciales y que aún así, como ha quedado expresado, esta medida sí ha dificultado el acceso a la justicia y la administración de la misma, en términos que respeten el debido proceso y evitando de todas formas que el fenómeno de cosa juzgada fuera luego el que viniese a obstaculizar la realización de estos derechos procesales, de los cuales ella misma es una garantía.

\section{Análisis del fenómeno de cosa juzgada constitucional}

Para construir una propuesta, en la dialéctica que se ha venido desarrollando, es preciso dar explicación a la cosa Juzgada, con el fin de que los argumentos esbozados en la propuesta se correspondan con el sentido de esta garantía, ya que se ha dejado por concluido que este fenómeno ha constituido en casos como los precitados un obstáculo en la progresividad de los derechos en nuestro Estado. Así las cosas, se explica esta garantía del debido proceso, de acuerdo con referentes jurisprudenciales de la Corte en torno a este tema.

La cosa juzgada constitucional, regulada en la Constitución Política de Colombia en su artículo $243^{3}$, resulta una herramienta de carácter fundamental en nuestro Estado social de derecho, pues aporta la llamada seguridad jurídica que garantizará el respeto por el pronunciamiento hecho frente a un caso particular y la tranquilidad acerca de la firmeza en el pronunciamiento dado. La cosa juzgada constitucional da el carácter de definitiva, inmutable y vinculante a las decisiones emanadas de la Corte Constitucional.

Humberto Sierra Porto, magistrado de la Corte Constitucional, ha definido la cosa juzgada constitucional, así:

\footnotetext{
Constitución Política de Colombia 1991. Artículo 243. Los fallos que la Corte dicte en ejercicio del control jurisdiccional hacentránsito a cosa juzgada constitucional. Ninguna autoridad podrá reproducir el contenido material del acto jurídico declarado inexequible por razones de fondo, mientras subsistan en la Carta las disposiciones que sirvieron para hacer la confrontación entre la norma ordinaria y la Constitución.
} 
La cosa juzgada, en sentido amplio, es la fuerza que el Derecho atribuye normalmente a los resultados procesales. Esta fuerza se traduce en un necesario respeto y subordinación a lo dicho y hecho en el proceso. El proceso, en virtud de la figura de la cosa juzgada, se hace inacatable, y cosa juzgada no quiere decir, en sustancia, sino acatabilidad de lo que en el proceso se ha conseguido.

En tal sentido, la cosa juzgada tendrá como principal objetivo el evitar que haya doble pronunciamiento sobre un mismo suceso, buscará entonces que un pronunciamiento sea acatado y a la vez llene las expectativas de justicia evocadas por todo ciudadano.

Ya la Corte Constitucional en la sentencia C- 543 de 1992, expresó que

El fin primordial de este principio radica en impedir que la decisión en firme sea objeto de nueva revisión o debate, o de instancias adicionales a las ya cumplidas, o que se reabra el caso judicial dilucidado mediante el fallo que reviste ese carácter, con total independencia de su sentido o alcances, dotando de estabilidad y certeza las relaciones jurídicas y dejando espacio libre para que nuevos asuntos pasen a ser ventilados en los estrados judiciales.

No se podrá entonces, válidamente, pretender reabrir un litigio que trate sobre el mismo objeto, con unas mismas peticiones y con identidad de las partes, pues es precisamente ello lo que está amparado por la figura de cosa juzgada constitucional que además tendrá un efecto erga omnes; para que una decisión alcance el valor de cosa juzgada se requiere:

- Identidad de objeto, es decir, la demanda debe versar sobre la misma pretensión material o inmaterial sobre la cual se predica la cosa juzgada. Se presenta cuando sobre lo pretendido existe un derecho reconocido, declarado o modificado sobre una o varias cosas o sobre una relación jurídica. Igualmente se predica identidad sobre aquellos elementos consecuenciales de un derecho que no fueron declarados expresamente.

- Identidad de causa petendi (eadem causa petendi), es decir, la demanda y la decisión que hizo transito a cosa juzgada deben tener los mismos fundamentos o hechos como sustento. Cuando además de los mismos hechos, la demanda presenta nuevos elementos, solamente se permite el análisis de los nuevos supuestos, caso en el cual, el juez puede retomar los fundamentos que constituyen cosa juzgada para proceder a fallar sobre la nueva causa.

- Identidad de partes, es decir, al proceso deben concurrir las mismas partes e intervinientes que resultaron vinculadas y obligadas por la decisión que constituye cosa juzgada. (Pág. web Gerencie.com, s.f.) 
En la sentencia C-720 de 2007, el efecto de cosa juzgada constitucional apareja, al menos, las siguientes consecuencias:

En primer lugar, la decisión queda en firme, es decir, que no puede ser revocada ni por la Corte ni por ninguna otra autoridad. En segundo lugar, se convierte en una decisión obligatoria para todos los habitantes del territorio. Como lo ha reconocido la jurisprudencia, la figura de la cosa juzgada constitucional promueve la seguridad jurídica, la estabilidad del derecho y la confianza y la certeza de las personas respecto de los efectos de las decisiones judiciales.

\section{De la posibilidad de hacer excepciones a los derechos y garantías en el Estado social de derecho}

Como otro antecedente a la propuesta, es preciso clarificar la posibilidad que existe en nuestro Estado de hacer ciertas excepciones a los derechos, bajo la máxima de que estos no son ilimitados. Se referencian a continuación apuntes jurisprudenciales que ha hecho nuestro máximo tribunal constitucional al respecto.

El derecho al debido proceso, como todos los derechos fundamentales, no es un derecho absoluto. Su ejercicio, ha dicho la Corte, puede ser objeto de limitaciones que resultan ser necesarias para realizar otros principios superiores o para garantizar otros derechos fundamentales que en cierto momento pueden verse confrontados con aquel.(...) Otros derechos, en cambio, y tal es el caso del derecho de defensa y de contradicción, pueden verse limitados para garantizar intereses legítimos alternos, siempre y cuando su núcleo esencial no resulte desconocido, y las limitaciones establecidas sean razonables y proporcionadas.(Corte Constitucional, 2001, C-648)

El derecho al debido proceso, como todos los derechos fundamentales, no es un derecho absoluto. Su ejercicio, ha dicho la Corte, puede ser objeto de limitaciones que resultan ser necesarias para realizar otros principios superiores o para garantizar otros derechos fundamentales que en cierto momento pueden verse confrontados con aquel. En efecto, la jurisprudencia ha detectado cómo en múltiples ocasiones los distintos derechos constitucionales pueden verse contrapuestos entre sí. Así, para citar ejemplos, ha dicho:

El sistema constitucional se compone de una serie de derechos fundamentales que se confrontan entre sí. Ello, no sólo porque se trata de derechos que han surgido históricamente como consecuencia de la aparición de valores contrarios, sino porque, incluso, los que responden a sistemas axiológicos "uniformes" pueden verse enfrentados o resultar opuestos a objetivos colectivos de la mayor importancia constitucional. Así, para solo mencionar algunos ejemplos, el derecho 
a la libertad de expresión (C.P. art. 20) se encuentra limitado por el derecho a la honra (C.P. art. 21), al buen nombre y a la intimidad (C.P. art. 15) y viceversa ; el derecho de asociación sindical no se extiende a los miembros de la fuerza pública (C.P. art. 39); el derecho de huelga se restringe en nombre de los derechos de los usuarios de los servicios públicos esenciales (C.P. art. 56); el derecho de petición está limitado por la reserva de ciertos documentos para proteger intereses constitucionalmente valiosos (C.P. art. 23 y 74); el derecho al libre desarrollo de la personalidad se encuentra limitado por "los derechos de los demás y el orden jurídico" (C.P. art. 16), etc.

Ahora bien, para resolver este tipo de contradicciones que en ocasiones se presentan entre los distintos derechos e intereses constitucionalmente tutelados, las normas superiores sólo excepcionalmente traen fórmulas de solución. Por ejemplo, ellas señalan expresamente la prevalencia de los derechos de los niños sobre los de los demás (C.P. art. 44). No obstante, de manera general no indican en qué forma debe ser resuelta por el operador jurídico la tensión comentada, siendo necesario que la armonización de todos los principios, valores y derechos superiores se lleve a cabo estableciendo límites y restricciones que permitan articular los intereses constitucionales en juego. Es por ello que la Corte Constitucional (1995, C-578) ha dicho:

Los derechos fundamentales, no obstante su consagración constitucional y su importancia, no son absolutos y, por tanto, necesariamente deben armonizarse entre sí y con los demás bienes y valores protegidos por la Carta, pues, de lo contrario, ausente esa indispensable relativización, la convivencia social y la vida institucional no serían posibles.

Igualmente, en sentencia C-830 de 2010, la Corte manifestó:

Derechos y libertades son relativos y no absolutos puesto que el legislador puede señalar límites en función del bien común y el interés social en todas las manifestaciones que considera el ordenamiento y, además de esas restricciones, introducir en el ejercicio de los derechos y libertades los criterios que sean adoptados en el marco de las políticas económicas y fiscales de conformidad con las reglas constitucionales sobre el particular.

Restricción de derechos puede darse con el único propósito de cumplir fines constitucionalmente valiosos, destinados a la protección del interés general. Las previsiones constitucionales llevan a concluir que la delimitación conceptual de las libertades económicas se inserta en el equilibrio entre el reconocimiento de las garantías necesarias para el intercambio económico y la obligación estatal correlativa de intervenir en el mercado con el fin de (i) garantizar la supremacía del bien común, representado en los objetivos identificados por el Constituyente 
como propios de ese interés general; y (ii) corregir, en el marco de la protección de la igualdad de oportunidades, las imperfecciones de dicho mercado que se conformen como barrera para el acceso de los bienes y servicios de las personas de menores ingresos o en condiciones de debilidad manifiesta.

También, mediante sentencia C 475 de 1997, expresó:

Si el sistema constitucional estuviese compuesto por derechos ilimitados sería necesario admitir (1) que se trata de derechos que no se oponen entre sí, pues de otra manera sería imposible predicar que todos ellos gozan de jerarquía superior o de supremacía en relación con los otros; (2) que todos los poderes del Estado, deben garantizar el alcance pleno de cada uno de los derechos, en cuyo caso, lo único que podría hacer el poder legislativo, sería reproducir en una norma legal la disposición constitucional que consagra el derecho fundamental, para insertarlo de manera explícita en el sistema de derecho legislado. En efecto, de ser los derechos "absolutos", el legislador no estaría autorizado para restringirlos o regularlos en nombre de otros bienes, derechos o intereses constitucionalmente protegidos. Para que esta última consecuencia pueda cumplirse se requeriría, necesariamente, que las disposiciones normativas que consagran los "derechos absolutos" tuviesen un alcance y significado claro y unívoco, de manera tal que constituyeran la premisa mayor del silogismo lógico deductivo que habría de formular el operador del derecho.Como la concepción "absolutista" de los derechos en conflicto puede conducir a resultados lógica y conceptualmente inaceptables, la Carta opta por preferir que los derechos sean garantizados en la mayor medida posible, para lo cual deben sujetarse a restricciones adecuadas, necesarias y proporcionales que aseguren su coexistencia armónica.

\section{Síntesis-propuesta}

La síntesis elaborada por el grupo reconcilia los argumentos de la tesis con los de la antítesis en torno a la solución de los problemas jurídicos que a lo largo de todo el trabajo se han venido exponiendo y toma como base las aclaraciones previas.

Para reconciliar los argumentos es preciso concluir que si bien es necesaria la regresión de ciertos derechos en nuestra sociedad, como ha quedado expresado, bien sea por la medida legislativa o su declaratoria de exequibilidad, es preciso que se siga este procedimiento:

1. El grupo investigador propone que la Corte Constitucional deba, cada vez que se realice una regresión en los derechos expresa (mediante el test de no regresividad en el examen de constitucionalidad), en los términos en que se ha expresado anteriormente a través de las sentencias de constitucionalidad, realizar un seguimiento al cumplimiento de los objetivos que se han privilegiado para hacer 
la regresión. Bien un seguimiento juicioso a un comité que para el efecto haya sido designado por el legislador, o a faltar de este, quede la Corte en facultad de nombrar uno, en términos que sean constitucionales (razonabilidad y proporcionalidad).

2. Que aun no siendo expresa esa regresión, mediante un nuevo mecanismo, sin mayor formalidad, sólo que sea escrito, pueda cualquier ciudadano solicitar a la Corte que se declare una medida legislativa como regresiva y a ésta se le haga el mismo seguimiento en los términos del numeral anterior.

Esto, fundamentado en el asombroso garante constitucional que es la Corte Constitucional como se ha expresado ya en lo argumentado hasta acá.

La naturaleza jurídica de este seguimiento es el de una institución jurídica que tenga la fuerza de control constitucional de las medidas regresivas, es decir, con efectos vinculantes erga omnes.

El objeto de dicho seguimiento será sin duda la valoración de las condiciones en que se cumpla o no el objetivo general que se colocó por encima de los derechos, condicionando, como es obvio, que sólo se siga en la aplicación de la normatividad, siempre que se estén cumpliendo.

Por supuesto, quedaría la Corte facultada para suspender la ejecución de la norma, mientras el seguimiento no se haya llevado a cabo e incluso declarar su inexequibilidad, tan pronto como sea demandada.

3. El problema de la regresión inefectiva de derechos se acentúa cuando la Corte Constitucional en sus sentencias, decide no volver a fallar de fondo en la cuestión alegada como regresiva e inefectiva. Así, el grupo propone que para los efectos de regresión de derechos, se haga una excepción a la aplicación de la norma general de garantía procesal, cosa juzgada, tomando como argumentos jurídicos los expresados previamente, considerando que al ser la cosa juzgada una garantía del debido proceso y pudiendo este exceptuarse en el marco de un Estado social de derecho que no consagra derechos absolutos, además existiendo un nuevo marco fáctico es preciso que se haga una nueva revisión de la norma cuestionada. $\mathrm{O}$ de no ser posible hacer la excepción, se tome entonces que al cambiar el marco fáctico que da lugar al examen de constitucionalidad, se entienda que no se configuró la cosa juzgada, tomando como referente que en cualquiera de los dos eventos sería deber de la Corte volver a revisar de fondo la norma acusada, en los términos expuestos anteriormente. 
El objeto de esa excepción jurídica sería el de permitir que ante la inefectividad de la regresión de los derechos, pueda la Corte volver a fallar de fondo en la cuestión y sobre todo exhortar al legislador sobre la toma de una nueva medida para resolver el problema existente que pudo conducir a la regresión.

La excepción debe ser propuesta por el accionante en control abstracto, aunque la Corte podría aplicarla aun en los casos en que no sea ostensible la regresión inefectiva. Este nuevo instrumento jurídico que acompañará las demandas de inconstitucionalidad, deberá argumentarse por quien pretenda hacerla valer y, como es lógico, el accionante adjuntará prueba siquiera sumaria de que la medida regresiva no ha cumplido con los objetivos. Así las cosas, la Corte hará una nueva revisión, quedando facultada para decretar las pruebas pertinentes y con fundamento en ello fallar de fondo nuevamente, última sentencia que sí haría tránsito a cosa juzgada, resolución de la cual ante la inexequibilidad, exhortará con fuerza vinculante al legislador para que se pronuncie al respecto.

Será requisito para que proceda la excepción que se haya llevado a cabo, el seguimiento de que se habló en el punto anterior; si no ha habido seguimiento, la demanda de inconstitucionalidad no debe llevar como pretensión la excepción sino la inexequibilidad misma.

\section{Conclusión}

Hecho el ejercicio investigativo, el grupo concluye que la regresión de derechos no es sólo un problema jurídico, es un problema social. La cultura por la que se debe propender y en especial en esos espacios académicos en que se forma al jurista, es una cultura antiregresiva, pues no sólo el legislador o las sentencias de constitucionalidad podrían contribuir en la regresión de los derechos, sino que la misma conducta humana se orienta a veces para tomar actitudes que además de regresivas, pisotean y no sólo inefectivamente sino injustamente los derechos de los demás; por ello, la última invitación es para toda la sociedad colombiana, en un llamamiento para no actuar en contra de los derechos de nadie, pues no sólo los organismos estatales están llamados a garantizarlos, sino que cada ser humano debe respetar el derecho ajeno y velar por el propio, en la lógica de ese contrato social que le dio origen al Estado hace ya tantos años.

Hagamos entonces que la primera conducta progresiva en materia de derechos, sea la nuestra, la cotidiana... 
Derecho ₹ Realidad

\section{Lista de Referencias}

Banco de la República. (2005). Resolución. Recuperado de http://www.banrep.gov.co/ sala-prensa/com2012.html

Congreso de la República. (2011). Proyecto de Ley 005 de 2011.

Consejo de Estado. (2006, 4 de dic.). Sentencia. Sala de lo Contencioso Administrativo, Sección Tercera. C.P. Dr. Mauricio Fajardo Gómez. Actor: municipio de Tauramena. Demandado: Gundisalvo Vega $S$.

Corte Constitucional. (1992). Sentencia C- 543. M.P. Dr. José Gregorio Hernández Galindo.

Corte Constitucional. (1995). Sentencia C-578. M.P. Dr. Eduardo CifuentesMuñoz.

Corte Constitucional. (1997). Sentencia C 475. M.P. Dr. Eduardo CifuentesMuñoz.

Corte Constitucional. (2001). Sentencia C-648. M.P. Dr. Marco Gerardo Monroy Cabra.

Corte Constitucional. (2004). Sentencia C-038. M.P. Dr. Eduardo MontealegreLynett.

Corte Constitucional. (2007). Sentencia C-720. M.P. Dra. CatalinaBotero Marino.

Corte Constitucional. (2008). Sentencia C-034. M.P. Dr. Jaime Córdoba Triviño.

Corte Constitucional. (2008). Sentencia C-257. M.P. Dra. Clara Inés Vargas Hernández.

Corte Constitucional. (2010). Sentencia C-830. M.P. Dr. Luis Ernesto Vargas Silva.

Corte Constitucional. (2011). Sentencia C-598. M.P. Dr. Jorge IgnacioPreteltChaljub.

Corte Constitucional. (2011). Sentencia C- 228. M.P. Dr. Juan Carlos Henao Pérez.

Gerencie.com. (s.f.). Cosa juzgada constitucional. Recuperado de http:// www.gerencie.com/cosa-juzgada.html

Giacometto, A. (2007). Jurisprudencia constitucional en materia de conciliación prejudicial obligatoria. La Rioja:Dialdet.

Instituto Colombiano de Derecho Procesal. (2012). Proyecto de Código General del Proceso. Exposición de motivos.

Kelsen, H. (1960). Teoría pura del derecho.(Trad. de la $2^{\text {a }}$ ed. en alemán). México: Coyoacán.

La Guía 2000. (s.f.).Clasificación de los derechos humanos. Recuperado de http:// derecho.laguia2000.com/parte-general/clasificacion-de-los-derechos-humanos. 